\title{
Trends and regularities of energy development in Russia's eastern regions: methods and results of research
}

\author{
Alexander Sokolov, Svetlana Muzychuk*, and Roman Muzychuk, Melentiev Energy \\ Systems Institute of Siberian Branch of the Russian Academy of Sciences, Irkutsk, Russia
}

\begin{abstract}
Russia's energy sector is the basis for the national economic development. At present, the importance of the eastern direction in the energy policy of Russia is growing. A computer simulation of energy development processes in the eastern regions of Russia (Siberian and Far Eastern Federal Districts (SFD, FEFD)) is of great theoretical and practical value as an effective method for studying complex systems. The study is concerned with the energy sector of the eastern regions of Russia, energy saving and energy efficiency. The aim of the research is to identify the most significant factors affecting the energy efficiency of the economy of the eastern regions of Russia and quantify their impact by an energyeconomic analysis. The study uses the methods of economic-mathematical modelling, systems-, and statistical analysis, balance and indicative methods. The most significant factors affecting the energy efficiency of the economy in the eastern regions of Russia are reduction in specific fuel consumption; reduction of energy losses; rational consumption of fuel and energy resources. Measures to improve the fuel and energy balance of the eastern regions of Russia will improve the energy efficiency of the economy, which will improve the quality of life of the population.
\end{abstract}

\section{Introduction}

The main method of systems analysis of the energy sector is the development of consolidated energy balances, from the production of all types of energy resources to their final consumption. Such balances selecting the patterns of energy supply to different entities - from enterprises to the regions and the whole country, in order to identify the areas and proportions of energy development for the period ahead.

The main goal of the energy balances is to show the availability and use of energy resources in a certain territory and to determine the indices of energy efficiency. The energy intensity of Russia's gross regional product (GRP) significantly exceeds this index in the developed countries of the world. The manufacture of products with higher intensity requires more material, labour and financial resources. The increased costs of fuel and energy resources lead to a deterioration of the environment; acceleration of the fossil fuel deposits development and their depletion, which affects future generations. Thus, the

*Corresponding author: muz@isem.irk.ru 
growth of energy efficiency in the country and its regions is one of the most important priorities of the state energy policy and social and economic development.

We used computer models to assess the behaviour of the energy sector of the eastern regions under various development conditions and obtain new knowledge about the factors that influence the enhancement of energy efficiency.

The main stages of computer modelling of the energy development in the east of Russia are:

- Statement of the problem: energy development of the regions, given the growth of their energy efficiency and introduction of innovations;

- Development of a conceptual model: reliable and cost-effective supply of energy resources to consumers in the regions, in terms of interregional and export energy links;

- Development of a computer model system: external energy links of regions; energy consumption levels, given energy efficiency growth; primary energy production; energy resources transfer system; primary energy resources processing; final energy consumption;

- Computational experiments;

- Analysis and interpretation of the results.

In the process of research into the energy development in the eastern regions of Russia, we developed a system of computer models. This system of models includes balances of certain types of energy resources, consolidated energy balance, energy and statistical analysis of the regional energy balance.

\section{Relevance, scientific significance of the issue}

The indicator of low energy efficiency in the country is that the energy intensity of the gross domestic product in the Russian Federation is 2.5-3.5 times higher than in the US and Europe. Low energy efficiency considerably restrains the rates of the economic development and decreases the competitiveness of the Russian products in the world markets. In the eastern regions of Russia the indices of energy intensity of GRP are 2-3 times higher than average in Russia.

The use of energy resources is viewed as a system in terms of the whole complex of interrelations between producers, suppliers and consumers. Generally, the energy use situation can be seen from the consolidated energy balance, which unites the production and consumption balances for certain types of energy resources.

The study on the energy development and the problems of energy saving and energy efficiency based on the energy balance in Russia was started in 1920-1930 (Krzhizhanovsky G.M., Veits V.I., Rusakovsky E.A., Probst A.E.), continued in 1950-1960 (Melentiev L.A., Starikovich M.A., Steinhaus E.O.) and in 1970-1980 (Nekrasov A.S., Sinyak Yu.V., Yanpolsky V.A., Makarov A.A., Vigdorchik A.G.). Later, many prominent Russian scientists (Bashmakov I.A. [1], Bushuev V.V. [2], Galieva T.M. [3], Gasho E.G., Mastepanov A.M., Suslov N.I., Troitsky A.A., Chernova G.V., Churashev V.N., Chupyatov V.V., Filippov S.P., and others) developed the studies in a new economic environment.

The issues of optimal use of energy resources and analysis of energy efficiency are also discussed in the publications by foreign authors (Rosenfeld A.H., Patterson M., Haas R., Hotelling H., Solow R.M., Nordhaus William D., Chandler Morse, Lakshmanan T.R., Ratick Sam, Herring Horace, Sorrel S., and others).

\section{Statement of the problem}

Many policy documents adopted in Russia at the highest level state that the increase in the energy efficiency of the Russian economy is one of the paramount priorities of the national 
policy. This can be achieved through wider adoption of energy saving technologies and equipment, a more complete and comprehensive use of energy resources, reduction in their losses, application of innovative solutions in the energy sector, and use of competitive advantages in the foreign markets.

The energy potential of Eastern regions, necessary for sustainable social and economic development and for the energy cooperation with NEA countries, can be determined using a systems analysis based on the energy balance.

The energy balance is one of the key tools to find out the disproportions in forecasting and establishing the balance between demand and supply of energy resources from production to their consumption. It serves as the main information basis to determine the indices of energy efficiency.

The projected energy balance should be a basic constituent of the forecast of the economic and energy development. Furthermore, it should specify the goals and objectives of the energy efficiency enhancement.

At the same time, of special importance is the analysis of current state of the energy sector and energy balance, since such an analysis will make it possible to improve the quality of the forecast of further energy development.

\section{Statement of the problem}

Extending the research of Russian and foreign scientists in this field and taking into account the latest policy documents of the Government of the Russian Federation in the field of energy, we have generated a methodological approach to study the development of regional energy sector in the east of Russia.

The novelty of the approach is the integrated application of a number of research methods that complement each other. Based on these methods we can identify the most important factors and directions of energy efficiency growth; make forecasts of the development of the regional energy sector that corresponds to the forecasts for the development of the economy and energy in Russia.

The methodological approach includes $[4,5]$ :

- A system of models and databases intended to analyse and forecast alternative scenarios for the development of energy sector in Siberia and the Far East (with details for the entities of the Russian Federation in these territories), taking into account interregional and international supplies;

- Economic and mathematical models for the formation of balance reports and future energy balances;

- Methods of assessing the energy efficiency of the regional economy based on energy balances;

- Methods of statistical analysis that identify the most significant factors affecting the energy efficiency of the regions.

Modelling of the energy development of the eastern regions of Russia is carried out according to the following scheme (Fig. 1).

The information and computer system (ICS) created for the formation of the accounting and forecasted energy balances of the regions of Siberia and the Far East (ICS "Energy Balance of Siberia and the Far East") consists of an information and reference system (IRS) and a system of models $[4,5]$.

The IRS provides an interface for accessing data in a form convenient for analysis (tables, graphs, diagrams). The system of models of the ICC "Energy balance of Siberia and the Far East" covers the economic and mathematical models: single-product balances of certain types of energy resources, summary energy balances, economic analysis, and models of statistical analysis of factors affecting the energy efficiency. 


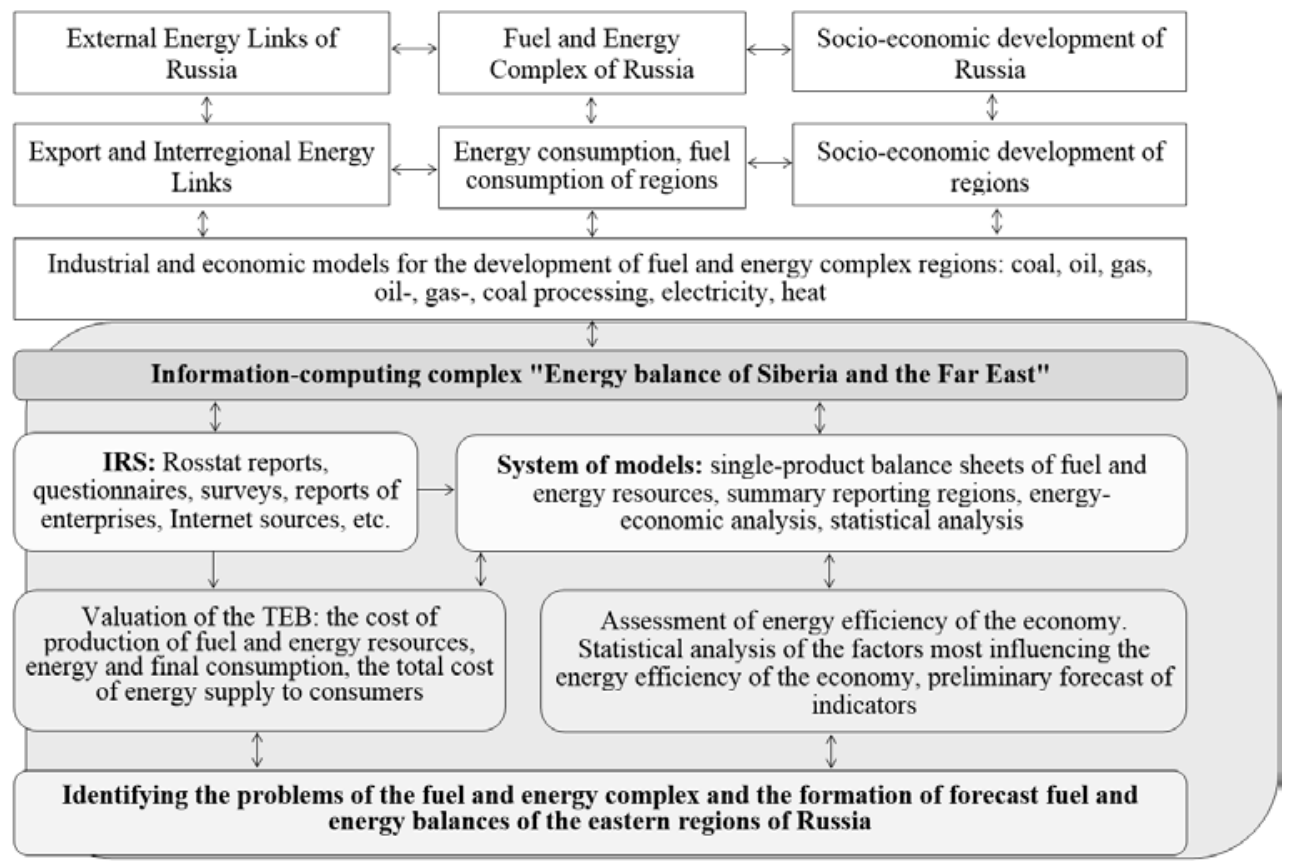

Fig. 1. The scheme for modelling the energy development processes in the eastern regions of Russia.

An analysis of the overall energy balances over several past years reveals the main energy sector features, which are typical of a certain region, and shows the tendencies of changes in the balance indices, which can improve long-term forecasts of the energy development.

\section{An analysis of energy sector of eastern regions of Russia}

Fig. 2 presents the energy balance of Russia's eastern regions in 2016 in a simplified form through a scheme of energy flows.

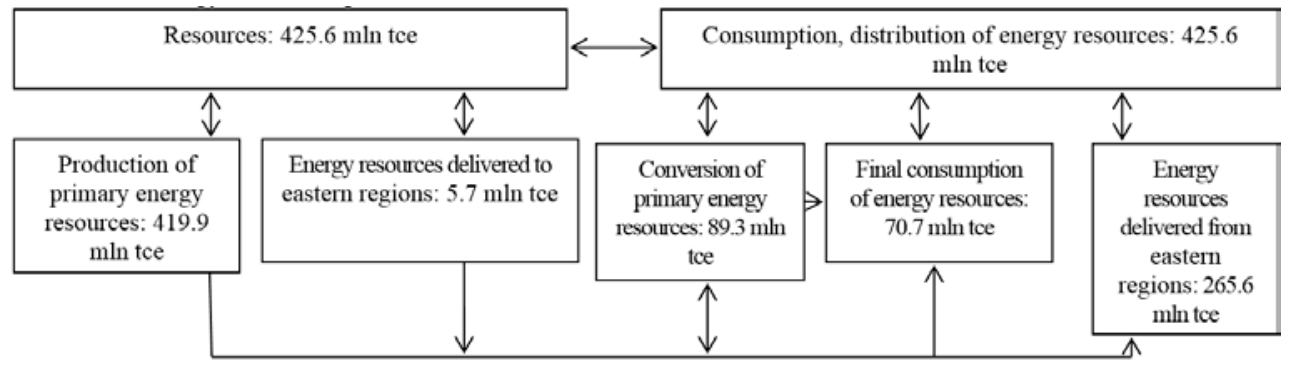

Fig. 2. The scheme of energy flows in the eastern regions, 2016. Author's estimation.

An analysis of energy balances of the eastern regions for 2010-2016 showed that the available energy resources in the regions could fully meet their growing demand and provide planned export supplies. The indicators of energy-, electricity-, and heat capacity of GDP in the eastern regions are higher than those of Russia as a whole, respectively - by $29.5 ; 55.8$ and $36 \%$, which characterizes the lower energy efficiency of their economy (Table). 
Table. Indices of energy intensity for Russia and eastern regions

\begin{tabular}{|l|c|c|c|c|}
\hline \multicolumn{1}{|c|}{ Index } & Russia & SFD & FEFD & $\begin{array}{c}\text { Eastern } \\
\text { regions }\end{array}$ \\
\hline Energy-GRP ratio, tce/mln RUB & 12.2 & 18.3 & 11.1 & 15.8 \\
\hline Electricity-GRP ratio, kWh/thousand RUR & 16.3 & 32.2 & 13.0 & 25.4 \\
\hline Heat-GRP ratio, Gcal/thousand RUR & 20.0 & 32.0 & 18.2 & 27.2 \\
\hline Energy utilization efficiency at power plants, \% & 56.4 & 54.5 & 49.3 & 53.4 \\
\hline Energy utilization efficiency at boiler plants, \% & 89.6 & 74.5 & 72.4 & 74.1 \\
\hline Energy utilization efficiency of final consumption, \% & 52.6 & 43.5 & 46.2 & 44.2 \\
\hline
\end{tabular}

The use of energy resources in the energy sector and the economy of eastern regions is less efficient than on average in Russia. The energy efficiency coefficients of boiler plants, thermal power plants and final consumers, are $17.3,16$, and $5.3 \%$ respectively below the Russian average.

Technological indicators of energy efficiency in the eastern regions (specific fuel consumption and losses in networks) exceed the corresponding figures for the entire country:

- The specific costs for electricity generation at thermal power plants are $13.2 \%$ higher;

- The specific costs for heat production at thermal power plants are 3.9\% higher;

- Unit costs for boiler plants are $20.9 \%$ higher;

- Electricity losses in the networks are $12.2 \%$ higher;

- Heat losses in the networks are $42.9 \%$ higher.

Within the period of 2010-2016, the specific costs of power and heat production in the eastern regions did not decrease but on the contrary, showed an increase in these indices by $2-3 \%$. This testifies to the fact that energy-generating companies involve the energy conservation technologies to a small extent. However, the improvement in the situation requires considerable investment to upgrade the equipment and adopt advanced technologies in the energy sector.

From 2010 to 2016, there was a reduction in energy carrier losses in the networks. This mainly refers to electricity. Electricity losses in the networks decreased by $35 \%$, which was largely due to the installation of metering and control devices. This, in turn, allowed a considerable reduction in commercial losses. Heat losses decreased insignificantly due to heavy wear in heat networks. Their restoration is impossible without substantial investment.

The energy sector of the eastern regions is experiencing many problems, the most important of which are as follows:

- The aging of the main production capacities worsens the technical and economic performance of companies and increases the energy losses in the networks, which in turn requires large-scale investments in modernization and technical re-equipment;

- The presence of a significant share of coal in the fuel balances of the eastern regions worsens the ecological situation and requires a reduction in coal consumption and an increase in consumption of natural gas and renewable resources;

- Lower energy efficiency indices in the eastern regions compared with the whole country indicate a great potential for their increase;

- Natural energy resources are scattered throughout the eastern regions of Russia; the largest and most promising deposits are located in poorly developed, inaccessible northern regions without transport infrastructure, which hampers their development.

The problems encountered in the energy sector of Eastern regions can be comprehensively solved only if there is a coordinated long-term strategy for energy interaction between the regions in the course of establishment of a common energy market 
considering energy export to NEA countries. This will make it possible to use the huge energy potential of Russia's East in a reasonable way.

\section{Conclusions}

The created model-computer system allowed carrying out research of the energy sector of the eastern regions of Russia.

One of the most important conditions of sustainable socioeconomic development for Eastern regions is the improvement of energy efficiency of the economy. The energy sector will play a special role in solving this problem, which will consist in improving the energy balance structure.

The main ways to improve the energy balance structure of Eastern regions are:

- Increasing the share of natural gas and renewable resources in the energy balance, which will make it possible to meet the demand for energy resources at lower specific costs and reduce the human impact on the environment;

- Constructing oil and gas processing plants, which will allow advanced processing of hydrocarbons and a higher value-added products;

- Reducing the energy production, transportation, and consumption losses;

- Enhancing coal processing in order to improve the quality and competitiveness of coal products in Eastern regions, and in distant prospect, to produce advanced processing products (smokeless fuel briquettes, agrochemicals, etc.);

- Effectively using renewable energy sources for consumers in remote areas in order to improve energy supply reliability and reduce the losses of energy carriers in the networks.

\section{Acknowledgements}

The work was carried out within the framework of the scientific project XI.174.2.2 of the program of fundamental research of the SB RAS, reg. No. AAAA-A17-117030310435-0

\section{References}

1. I.A. Bashmakov. Energy policy. Fuel and energy balance as a tool for analysis, forecasting and indicative planning of energy development, 2, pp.16-25. (2007).

2. V.V. Bushuev, A.A. Troitsky Energy: Economics, Technology, Ecology. Energy Efficiency and the Russian Economy, 5, pp. 10-19. (2004).

3. T.M. Galieva, A.M. Masterpanov. Energetic policy. About methodology of development of fuel and energy balances., 3, pp. 21-27. (2003).

4. B.G. Saneev, A.D. Sokolov, S.Yu. Muzychuk, R.I. Muzychuk. Bulletin of the Russian Academy of Sciences. Energy. Fuel and energy balances in the system of complex studies of the development of the regional energy industry, 2, pp. 21-35. (2011).

5. B.G. Saneev, A.D. Sokolov, S.Yu. Muzychuk, R.I. Muzychuk. Energy policy. Energyeconomic analysis of the current status of the regional fuel and energy complexes of the Russian East, 5, pp. 14-22. (2016). 